\title{
PAPERS
}

\section{Omeprazole promotes proximal duodenal mucosal bicarbonate secretion in humans}

\author{
A Mertz-Nielsen, J Hillingsø, K Bukhave, J Rask-Madsen
}

\begin{abstract}
The proton pump inhibitor, omeprazole, surprisingly resulted in higher rates of proximal duodenal mucosal bicarbonate secretion than previously reported using an $\mathrm{H}_{2}$ receptor antagonist for gastric acid inhibition. Gastroduodenal perfusions were performed in healthy volunteers to evaluate whether this incidental finding is explained by more potent gastric acid inhibition by omeprazole or might be caused by the different mode of drug action. Basal and stimulated gastric and duodenal bicarbonate secretion rates were measured in the same subjects in control experiments $(n=17)$ and after pretreatment with high dose omeprazole $(n=17)$ and ranitidine $(n=9)$, respectively, by use of a technique permitting simultaneous measurements. Concentrations of bicarbonate were measured in the respective effluents by the method of back titration. Both omeprazole and ranitidine completely inhibited gastric acid secretion (pH 6.9 v 6.8; p>0.05). Omeprazole caused higher rates of basal (mean (SEM)) (597 (48) $v \quad 351 \quad$ (39) $\mu \mathrm{mol} / \mathrm{h}$; $\mathrm{p}<0.02)$ and vagally stimulated $(834(72) v$ 474 (66) $\mu \mathrm{mol} / \mathrm{h} ; p<0.02$ ), but not acid stimulated (3351 (678) $v$ v. $2550 \quad$ (456) $\mu \mathrm{mol} / \mathrm{h} ; \mathrm{p}>0.05)$ duodenal bicarbonate secretion compared with control experiments. Also the combination of omeprazole and ranitidine increased $(p=0.05)$ duodenal bicarbonate secretion, while ranitidine alone caused no change in either basal or stimulated secretion. In the stomach basal as well as vagally stimulated bicarbonate secretion was independent of the means of acid inhibition. These results show that the proton pump inhibitor, omeprazole, promotes proximal duodenal mucosal bicarbonate secretion apparently independent of its gastric acid inhibitory effect. The mechanism of action remains speculative.

(Gut 1996; 38: 6-10)
\end{abstract}

Keywords: bicarbonate secretion, duodenum, omeprazole, stomach, ranitidine.

Previous work has shown the existence of a $\mathrm{pH}$ gradient at the luminal surface of the gastroduodenal mucosa generated by active secretion of bicarbonate into the mucus gel layer. ${ }^{12}$ As bicarbonate comprises the first line of defence against luminal acid and pepsin, recent research has focused on mucosal bicarbonate transport mechanisms both in experimental animals and in humans. ${ }^{3}$ The effect of various antiulcer drugs on gastroduodenal bicarbonate secretion has been investigated in several studies, ${ }^{4}$ among which a few have concentrated on the effect of the proton pump inhibitor, omeprazole. Administration of omeprazole to cats has resulted in both reduced $^{5}$ and increased ${ }^{6}$ rates of gastric bicarbonate secretion, while duodenal mucosal bicarbonate secretion in cats ${ }^{7}$ and in rats ${ }^{8}$ seems unaffected. Although relevant for clinical use in the treatment of acid related disorders, the potential effect of proton pump inhibitors on human gastroduodenal mucosal bicarbonate secretion has not previously been considered.

Incidentally, we observed that omeprazole resulted in higher rates of basal and vagally stimulated proximal duodenal mucosal bicarbonate secretion than previously reported using ranitidine as an inhibitor of gastric acid. To evaluate whether this finding might be explained by more potent inhibition of gastric acid by omeprazole or by the different mode of drug action, gastric and duodenal bicarbonate secretion rates were determined by use of a technique permitting simultaneous measurements. ${ }^{8}$ The same healthy volunteers were studied in control experiments without acid inhibition and after administration of omeprazole and ranitidine, respectively, using supramaximal, equipotent doses sufficiently large to obtain total inhibition of gastric acid secretion. In supplementary experiments, the combination of omeprazole and ranitidine on basal duodenal mucosal bicarbonate secretion was studied.

\section{Methods}

Healthy volunteers

Twenty one healthy volunteers (12 men and nine women, median age 32 years, range 24-50), with no history of gastrointestinal or other medical diseases, consented to the study protocol. None of the healthy volunteers had ingested aspirin, non-steroidal anti-inflammatory drugs, or alcohol during the week before 
entering the study, which was carried out according to the Helsinki II Declaration and approved by the ethics committee of Copenhagen and Frederiksberg.

\section{Experimental design}

Three series of experiments were performed. In the first series eight volunteers had simultaneous gastric and proximal duodenal perfusions twice (isotonic saline) with an interval of at least one week. The perfusions were performed in random order, that is, as one set of control perfusions (without acid suppression for determination of acid secretion in the stomach and bicarbonate secretion in the duodenum) and one set of experimental perfusions (for determination of bicarbonate secretion in the stomach and the duodenum) prior to which the subject was pretreated with a $60 \mathrm{mg}$ oral dose of omeprazole (Astra A/S, Albertslund, Denmark) once daily for three days and $80 \mathrm{mg}$ intravenously one hour before perfusion.

In the second series of experiments nine other volunteers had gastric and proximal duodenal perfusion three times. The perfusions were performed in random order and included one set of control perfusions (without acid suppression) and two sets of experimental perfusions prior to which the subject was pretreated with omeprazole as described above or with a $900 \mathrm{mg}$ oral dose of ranitidine (Glaxo Denmark A/S, Brøndby, Denmark) 12 and two hours before the experiment and ranitidine $50 \mathrm{mg} / \mathrm{h}$ intravenously during perfusion.

Supramaximal doses of omeprazole and ranitidine were chosen to ensure the complete suppression of gastric acid secretion required for determination of gastric bicarbonate secretion. ${ }^{9}$ Each perfusion in the first and second series of experiments included a 60 minute equilibration period followed by a 30 minute basal period and a 60 minute sham feeding period. In the second series of experiments the duodenal bulb was acidified $(\mathrm{HCl} 0 \cdot 1 \mathrm{M} ; 20$ $\mathrm{ml} ; 5 \mathrm{~min}$ ) after the sham feeding period and then the duodenum was perfused for 45 minutes with isotonic saline. Attempts to measure gastric bicarbonate secretion after acidification of the stomach failed, because it was impossible to remove all the instilled acid within 30 minutes.

In the third series of experiments another four healthy volunteers had proximal duodenal perfusion once to study the effect of the combination of omeprazole and ranitidine. Each subject was pretreated with omeprazole as described above and after a 60 minute equilibration period the duodenum was perfused during basal conditions for 60 minutes. Then a $50 \mathrm{mg}$ intravenous bolus injection of ranitidine was given. After a 30 minute equilibration period the duodenum was perfused for another 60 minutes during basal conditions. Ranitidine $50 \mathrm{mg} / \mathrm{h}$ was given intravenously during this final 90 minute period.

Simultaneous gastric and duodenal perfusions After an overnight fast a six channel tube (16
French, outside diameter $5.3 \mathrm{~mm}$, Pharmacia, Uppsala, Sweden) with three balloons was introduced orally. ${ }^{10} \mathrm{~A}$ Teflon coated guide wire was used for intubation (Amplatz Extra Stiff Wire Guide, outside diameter $0.9 \mathrm{~mm}$, William Cook Europe, Bjæverskov, Denmark) and the position of the tube was controlled by fluoroscopy. Proximal to a distal tungsten weight two button shaped inflatable latex balloons isolated a $3 \mathrm{~cm}$ long segment of the proximal duodenum. A pear shaped balloon in the distal stomach anchored the tube against the pylorus. The gastric balloon was inflated with $30 \mathrm{ml}$ of air and the duodenal balloons with $5-15 \mathrm{ml}$ of air. A double lumen gastric tube (16 French, AN 10 Anderson Samplers, Atlanta, GA, USA) was then placed in the distal antrum. The infusion port was located $8 \mathrm{~cm}$ proximal to the aspiration port. The isolated duodenal segment was perfused (Ivac 560 Pump, N C Nielsen, Glostrup, Denmark) with isotonic saline $(2 \mathrm{ml} / \mathrm{min} ; \mathrm{pH} 7 \cdot 0)$ using $\left[{ }^{51} \mathrm{Cr}\right]$ EDTA $(10 \mu \mathrm{Ci} / 1)$ as a non-absorbable marker. Similarly, the stomach was perfused with isotonic saline, containing phenol red (50 $\mathrm{mg} / \mathrm{l} ; \mathrm{pH} 7 \cdot 0$ ), at a constant rate of $5 \mathrm{ml} / \mathrm{min}$ (LKB 2115 Multiperpex Pump, Bromma, Sweden). The effluents were collected from the stomach by intermittent suction (Pump AB, Einar Egnell, Trollhättan, Sweden) and from the duodenal segment by gravity drainage. During the perfusions saliva was continuously removed by dental suction. This has previously been shown to minimise the amount of swallowed saliva that could contribute to gastric bicarbonate content during basal conditions, but especially during modified sham feeding. ${ }^{10}$

After the 60 minute equilibration period 15 minute gastric and duodenal samples were collected, except during modified sham feeding when gastric effluents were collected at five minute intervals. Modified sham feeding was performed using chewing gum (five pieces of fruit gum for 15 minutes). ${ }^{11}$ For acidification of the duodenal segment $20 \mathrm{ml}$ of $100 \mathrm{mM}$ $\mathrm{HCl}$ plus $54 \mathrm{mM} \mathrm{NaCl}$ were instilled into the segment for five minutes. In all subjects $\mathrm{pH}$ had returned to neutral values after 15 minutes when sampling was resumed.

\section{Analytical procedures}

Concentrations of hydrochloric acid in the gastric effluents from control experiments were determined by titration to $\mathrm{pH}=7.0$ with $0.1 \mathrm{M}$ $\mathrm{NaOH}$ (PHM82, Radiometer, Copenhagen, Denmark).

Concentrations of bicarbonate in $100 \mu l$ aliquots from gastric and duodenal effluents were determined in triplicate (Corning 965 Carbon Dioxide Analyzer, Corning Ltd, Halstead, England). ${ }^{12}$ Before analysis the samples were gassed with $\mathrm{CO}_{2}$ free nitrogen for five minutes to remove dissolved carbon dioxide. The Corning analyser was calibrated daily against 2.5 and $5.0 \mathrm{mM} \mathrm{NaHCO}$. The coefficients of variation were $12 \%(n=20)$ and $6 \%(n=20)$, respectively.

To determine the contamination of the 
TABLE I Basal gastric and duodenal pH measurements in 17 healthy volunteers during control conditions and after administration of omeprazole and ranitidine; mean (SEM)

\begin{tabular}{lll}
\hline & Stomach $p H$ & Duodenum $p H$ \\
\hline Control & $2 \cdot 32(0 \cdot 11)$ & $7 \cdot 40(0 \cdot 12)$ \\
Omeprazole & $6 \cdot 87(0 \cdot 08)$ & $7 \cdot 27(0 \cdot 06)$ \\
Ranitidine & $6 \cdot 82(0.09)$ & $7 \cdot 33(0 \cdot 11)$ \\
\hline
\end{tabular}

duodenal test segment with pancreatic juice, trypsin was measured in the duodenal effluents as previously described. ${ }^{10}$

Activities of $\left[{ }^{51} \mathrm{Cr}\right]$ and concentrations of phenol red were determined both in gastric and duodenal effluents and served as markers for recovery and contamination of the respective test segment. Activities of $\left[{ }^{51} \mathrm{Cr}\right]$ were measured by gammaspectrometry (Model 1185, Searle Nuclear Chicago Division, Chicago, IL, USA). Concentrations of phenol red were measured spectrophotometrically at $560 \mathrm{~nm}$ after alkalinisation $(\mathrm{pH}=11)$ by a $4+1$ dilution with a $0.5 \mathrm{M} \mathrm{Na}_{3} \mathrm{PO}_{4}$ solution.

\section{Calculations and statistical analyses}

Rates of acid and bicarbonate secretion were calculated as the mean of the two or four 15 minute values obtained during the basal periods. Similarly, the results obtained after stimulation were calculated as the mean of the three five minute values obtained in the stomach and the first 15 minute value obtained in the duodenum after start of modified sham feeding and as the mean of all values obtained in the duodenum after luminal acidification.

The results were expressed as means (SEM). The bicarbonate data were analysed using repeated measures analysis of variance (RMANOVA) for a two way model. The normality assumption for this model was tested with the Kolmogorov-Smirnov statistics. The Levene's statistic was used to test for equal variance. ${ }^{13}$ For most of the end points the normality assumption was violated. Thus, RMANOVA was performed on ranks. Student-Newman-Keul's multiple comparison test was used for statistical analyses. Comparison of recoveries, contamination, and $\mathrm{pH}$ values were performed with Student's $t$ test for paired variates. All $p$ values calculated were two tailed; the $\alpha$ value of significance was set at $0 \cdot 05$.

\section{Results}

\section{Validation of methods}

The mean recovery of the gastric and duodenal markers were $82(2) \%$ and $86(2) \%$, respectively, with no differences between control, omeprazole, and ranitidine experiments. Values of basal and stimulated gastric and duodenal fluid outputs, in addition to recoveries of phenol red, $\left[{ }^{51} \mathrm{Cr}\right]$ and trypsin, showed no significant differences $(p>0.3)$ between the groups. Only a small amount of gastric contents entered the duodenum $(0.3(0 \cdot 1) \%$, that is $0.01 \mathrm{ml} / \mathrm{min}$ ). The duodenogastric reflux equalled $0.8(0.2) \%$, that is $0.06 \mathrm{ml} / \mathrm{min}$. The contents of trypsin in the duodenal effluents were $0.6(0.2) \%$ of the average minimum trypsin output from the pancreas ${ }^{14}$ and a total of 11 samples from five subjects containing $\geqslant 25 \mu \mathrm{g} / \mathrm{ml}, 3 \%$ were excluded.

\section{pH Measurements}

Total inhibition of gastric acid secretion was achieved both after omeprazole and ranitidine administration and there was no significant difference between gastric $\mathrm{pH}$ values $(\mathrm{p}=0.8$; Table I). The duodenal $\mathrm{pH}$ measurements showed no significant $(\mathrm{p}>0.7)$ differences between control, omeprazole and ranitidine experiments, respectively (Table I).

\section{Gastric acid and bicarbonate secretion}

In control experiments basal and vagally stimulated gastric acid secretion was $4 \cdot 2(1 \cdot 1)$ $\mathrm{mmol} / \mathrm{h}$ and $7.9(1.7) \mathrm{mmol} / \mathrm{h}$, respectively.

The basal rates of gastric bicarbonate secretion were 401 (56) $\mu \mathrm{mol} / \mathrm{h}$ and 500 (104) $\mu \mathrm{mol} / \mathrm{h}$ after ranitidine and omeprazole administration, respectively. The difference was not statistically significant ( $p>0.05$; Table II). Modified sham feeding for 15 minutes caused a considerable rise $(p<0.05)$ in bicarbonate secretion both in ranitidine, and in omeprazole experiments (Table II).

\section{Proximal duodenal bicarbonate secretion}

The basal rates of duodenal mucosal bicarbonate secretion in control and ranitidine experiments were 351 (39) $\mu \mathrm{mol} / \mathrm{h}$ and 363 (63) $\mu \mathrm{mol} / \mathrm{h}$, respectively. In experiments with omeprazole the basal rate of proximal duodenal mucosal bicarbonate secretion was 597 (48) $\mu \mathrm{mol} / \mathrm{h}(\mathrm{p}<0.02)$ compared with control and ranitidine experiments, respectively (Table II and Figure).

Modified sham feeding for 15 minutes caused a moderate, but significant $(p<0.05)$, rise in bicarbonate secretion in all experiments. The response to modified sham feeding after omeprazole administration was significantly

TABLE II Effect of ranitidine, omeprazole, and the combination of omeprazole and ranitidine (Ome + Ran) on gastric and proximal duodenal mucosal bicarbonate secretion rates in healthy volunteers during basal conditions and after stimulation with modified sham feeding and luminal acid (0.1 M; $20 \mathrm{ml} ; 5 \mathrm{~min}) ;$ mean (SEM)

\begin{tabular}{|c|c|c|c|c|c|c|c|c|}
\hline & \multicolumn{3}{|c|}{ Gastric $\mathrm{HCO}_{3}-(\mu \mathrm{mol} / \mathrm{h})$} & \multicolumn{3}{|c|}{ Duodenal $\mathrm{HCO}_{3}-(\mu \mathrm{mol} / \mathrm{h} \times 3 \mathrm{~cm})$} & \multirow[b]{2}{*}{ Number } & \multirow[b]{2}{*}{ Luminal acid } \\
\hline & Number & Basal & Sham feeding & Number & Basal & Sham feeding & & \\
\hline $\begin{array}{l}\text { Control } \\
\text { Ranitidine } \\
\text { Omeprazole } \\
\text { Ome+Ran }\end{array}$ & $\begin{array}{r}17 \\
9 \\
17 \\
4\end{array}$ & $\begin{array}{l}-\overline{1}(56) \\
500(104) \\
-\end{array}$ & $\begin{array}{c}- \\
1316(412)^{\star} \\
916(196)^{\star} \\
-\end{array}$ & $\begin{array}{r}17 \\
9 \\
17 \\
4\end{array}$ & $\begin{array}{l}351(39) \\
363(63) \\
597(48) \dagger \\
528(78) \ddagger\end{array}$ & $\begin{array}{l}474(66)^{\star} \\
582(204)^{\star} \\
834(72)^{\star} \dagger \\
\quad-\end{array}$ & $\begin{array}{l}9 \\
9 \\
9\end{array}$ & $\begin{array}{c}2550(456)^{\star} \\
1752(573)^{\star} \\
3351(678)^{\star} \\
-\end{array}$ \\
\hline
\end{tabular}

${ }^{\star} \mathrm{p}<0.05$ compared with basal values; $\nmid \mathrm{p}<0.02$ compared with control and ranitidine (Student-Newman-Keul’s test); $\ddagger \mathrm{p}=0.05$ compared with control (Student's $t$ test). 


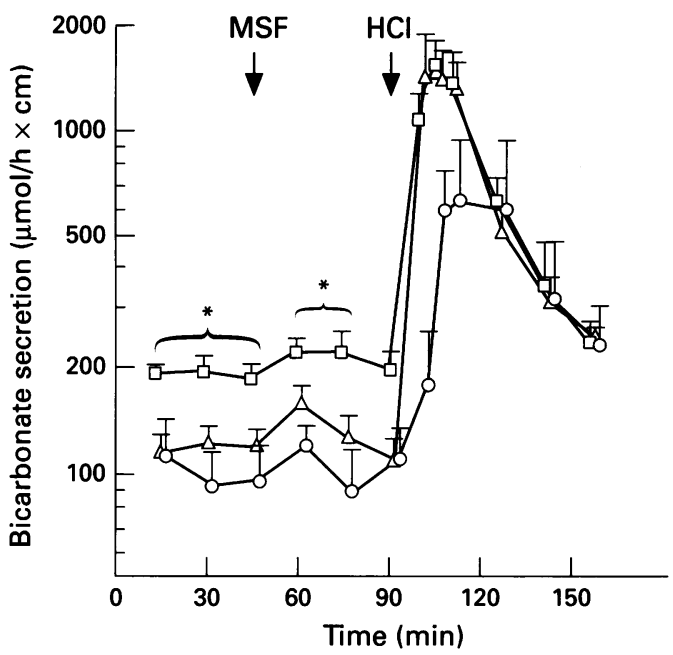

The effects of omeprazole $(\square-\square)$ and ranitidine ( $\mathrm{O}-\mathrm{O}$ ) on basal and stimulated (modified sham feeding $=M S F$; acid load $=H C l$ ) proximal duodenal mucosal bicarbonate acid load $=H C l$ ) proximal duodenal mucosal bicarbonate
secretion in healthy volunteers compared with no treatment $(\triangle-\triangle) ;$ mean (SEM). ${ }^{\star} p<0.02$ compared with control and ranitidine (Student-Newman-Keul's multiple comparison test).

$(p<0.02)$ higher than that seen in control and ranitidine experiments, respectively (Table II).

Luminal acidification of the duodenal bulb caused a considerable rise in bicarbonate secretion in all experiments. No significant differences in response were seen between control, omeprazole, and ranitidine experiments (Table II).

The basal rates of proximal duodenal bicarbonate secretion in the third series of experiments were 513 (93) $\mu \mathrm{mol} / \mathrm{h}$ after omeprazole alone and $528(78) \mu \mathrm{mol} / \mathrm{h}$ after the combination of omeprazole and ranitidine ( $p>0.05$; Table II).

\section{Discussion}

The results of this study show that the proton pump inhibitor, omeprazole, promotes proximal duodenal mucosal bicarbonate secretion, but not gastric bicarbonate secretion, in healthy volunteers, apparently independent of its acid inhibitory effect. While basal and sham feeding stimulated transport rates of bicarbonate in the duodenum were significantly higher in omeprazole experiments than in control and ranitidine experiments, it cannot be excluded that a type II error occurred when testing the results obtained during luminal acidification caused by a large variation between subjects.

The basal rates of gastric bicarbonate secretion seen in ranitidine and omeprazole experiments were in the same order of magnitude as those previously reported by others. ${ }^{915}$ Similarly, the rates of basal and stimulated proximal duodenal mucosal bicarbonate secretion seen in control and ranitidine experiments were similar to those obtained by others using the same six channel tube with three occluding balloons. 1216

The overall results of this study are, however, difficult to reconcile with much of the existing body of data relating to the action of omeprazole, considering that the compound is a highly specific, irreversible inhibitor of
$\mathrm{H}^{+}, \mathrm{K}^{+}$adenosine triphosphatase (ATPase), which blocks acid secretion in response to all modes of stimulation. ${ }^{17} \mathrm{H}^{+}, \mathrm{K}^{+}$ATPase inhibition has been reported to modulate ion transport in the small intestine of some amphibia, ${ }^{18}$ but this does not seem to occur in mammals. ${ }^{78}$ The mechanism responsible for the unexpected finding remains, therefore, obscure and theoretical considerations are speculative.

Nevertheless, omeprazole, compared with ranitidine, could inhibit acid secretion from heterotopic parietal cells in the duodenum ${ }^{19} 20$ with abnormal or lacking $\mathrm{H}_{2}$ receptors and thus seem to stimulate bicarbonate secretion. This is compatible with the finding that the combination of omeprazole and ranitidine resulted in the same rates of proximal duodenal mucosal bicarbonate secretion as omeprazole alone.

Omeprazole might also act to increase bicarbonate secretion indirectly by influencing the distribution of bicarbonate in the tissue, the mucosal blood flow, motility, or local nerves, while a role of Helicobacter pylori is unlikely in this paired design study. The possibility that omeprazole modulates neural reflexes would explain the discrepancy between results obtained in anaesthetised animals ${ }^{5-8}$ and conscious humans.

The possibility that duodenal bicarbonate secretion is inhibited by ranitidine, rather than promoted by omeprazole, should also be considered. If that was the case, histamine $\mathrm{H}_{2}$ receptor antagonists might be expected to decrease bicarbonate secretion both in the stomach and in the duodenum. Acid inhibition by supramaximal doses of ranitidine did not modulate gastric bicarbonate secretion, however, either in this study or in previous studies of healthy volunteers ${ }^{21}$ and duodenal mucosal bicarbonate secretion has been shown to be unaffected by ranitidine in animals. ${ }^{78}$ The apparent lack of effect of ranitidine could also be taken to imply that leakage of gastric acid occurred in control experiments despite the presence of occluding balloons. The rate of neutralised bicarbonate, however, as calculated from the appearance of the gastric marker in the duodenal effluents, did not exceed 20 $\mu \mathrm{mol} / \mathrm{h}$.

In conclusion, our results show that omeprazole promotes proximal duodenal mucosal bicarbonate secretion, but do not support the notion that histamine $\mathrm{H}_{2}$ receptor blockade inhibits mucosal bicarbonate secretion. While the normal basal output of bicarbonate from the duodenum equals approximately 1000 $\mu \mathrm{mol} / \mathrm{h}$ (duodenum about $9 \mathrm{~cm}$; see Table II), or $25 \%$ of basal gastric acid secretion, the omeprazole induced duodenal bicarbonate output amounts to approximately 1800 $\mu \mathrm{mol} / \mathrm{h}$, or $40 \%$ of basal gastric acid secretion, which could be neutralised by this alkali. Thus, the observed increase in duodenal neutralising capacity caused by omeprazole is likely to add to the well documented superiority of omeprazole (compared with histamine $\mathrm{H}_{2}$ receptor antagonists) in duodenal ulcer healing. 
Part of this work was presented at the Annual Meeting of the American Gastroenterological Association in May 1994 in New Orleans (Gastroenterology 1994; 106: A138) and was supported by a research grant from Astra A/B Mölndal, Sweden. The skilful technical assistance by Benedicte Bukhave is gratefully acknowledged.

1 Takeuchi K, Magee D, Critchlow J, Matthews J, Silen W. Studies of the $\mathrm{pH}$ gradient and thickness of frog gastric mucus gel. Gastroenterology 1983; 84: 331-40.

2 Flemström G, Kivilaakso E. Demonstration of a pH gradient at the luminal surface of rat duodenum in vivo and its dependence on mucosal alkaline secretion. Gastroenterology 1983; 84: 787-94.

3 Flemström G. Gastric and duodenal mucosal secretion of bicarbonate. In: Johnson LR, ed. Physiolgy of the gastrointestinal tract. 3rd edition. New York: Raven Press, gastrointestinal tract.

4 Guslandi M. Effects of anti-ulcer drugs on gastrointestinal bicarbonate secretion. Eur $\mathcal{F}$ Gastroenterol Hepatol 1990; 2: 27-31.

5 Guttu K, Røsok B, Gislason H, Fändriks L, Svanes K, Grønbech JE. Gastric bicarbonate secretion, acid secretion and mucosal blood flow during influence of pentagastrin and omeprazole in the cat. Scand $f$ Gastroenterol 1991; 26: 431-41.

6 Fändriks L, Stage L. Simultaneous measurements of gastric motility and acid-bicarbonate secretions in the anaesthetized cat. Acta Physiol Scand 1986; 128: 563-73.

7 Fändriks L, Jonson C. Effects of acute administration of omeprazole or ranitidine on basal and vagally stimulated omeprazole or ranitidine on basal and vagally stimulated in anaesthetized cats. Acta Physiol Scand 1990; 138: in anaesth $181-6$.

8 Knutson L, Flemström G, Gustavssom S, Jedstedt G, Lönnerholm G. $\mathrm{HCO}_{3}$-secretion in rat duodenum after treatment with omeprazole and ranitidine. Scand $f$ Gastroenterol 1987; 22: 87-90.

9 Odes HS, Hogan DL, Steinback JH, Ballesteros MA, Koss MA, Isenberg II. Measurement of gastric bicarbonate secretion in the human stomach: different methods produce discordant results. Scand f Gastroenterol 1992; 27: 829-36.
10 Mertz-Nielsen A, Hillingsø J, Eskerod O, Bukhave $\mathrm{K}$, Rask-Madsen J. Muscarinic $\mathbf{M}_{1}$ receptor inhibition Rask-Madsen J. Muscarinic $M_{1}$ receptor inhibition promotes gastric prostaglandin $\mathrm{E}_{2}$ synthesis in healthy promotes gastric prostaglandin $\mathrm{E}_{2}$
volunteers. Gut 1995; 36: 528-33.

11 Mertz-Nielsen A, Eskerod O, Bukhave K, Rask-Madsen J. Misoprostol inhibits gastric mucosal release of endogenous prostaglandin $E_{2}$ and thromboxane $B_{2}$ in healthy volunteers. Gut 1995; 36: 511-5.

12 Knutson L, Flemström G. Duodenal mucosal bicarbonate secretion in man. Stimulation by acid and inhibition by the alpha ${ }_{2}$-adrenoceptor agonist clonidine. Gut 1989; 30: 1708-15.

13 Jandel Scientific. Sigma Stat Manual. Microcomputer tools for the scientist. Revision SSD-1.0. Kuo J, Fox E: Augsburg, Germany, Jandel Scientific, 1992.

14 DiMagno EP. Alterations and consequences of interdigestive and poststimulatory human exocrine pancreatic secretion in health and disease. In: Polak JM, Bloom SR, secretion in health and disease. In: Polak JM, Bloom SR, Wright NA, Butler AG, eds. Basic science in gastro-
enterology. Physiology of the gut. Ware, Herts, UK: Glaxo enterology. Physiology of the gut. Ware,
Group Research Ltd, 1984: 251-66.

15 Forssell H, Stenquist B, Olbe L. Vagal stimulation of human gastric bicarbonate secretion. Gastroenterology 1985; 89: 581-6.

16 Ainsworth MA, Kjeldsen J, Schaffalitzky de Muckadell OB. Morphine inhibits secretion of bicarbonate from the human duodenal mucosa. Scand $f$ Gastroenterol 1990; 25 : 1066-75.

17 McTavish D, Buckley MM-T, Heel RC. Omeprazole. An updated review of its pharmacology and therapeutic use in updated review of its pharmacology and therape

18 White JF. Omeprazole inhibits $\mathrm{H}^{+}$secretion by amphiuma jejunum. Am f Physiol 1985; 248: G256-9.

19 Noach LA, Rolf TM, Bosma NB, Schwartz MP, Oosting J, Rauws EA, et al. Gastric metaplasia and Helicobacter pylori infection. Gut 1993; 34: 1510-4.

20 Carrick J, Lee A, Hazell S, Ralston M, Daskalopoulos G. Campylobacter pylori, duodenal ulcer, and gastric metaplasia: possible role of functional heterotopic tissue in ulcerogenesis. Gut 1989; 30: 790-7.

21 Guslandi M. Alkali secretion by the human stomach: effect of $\mathrm{H}_{2}$-blockers. Am f Physiol 1985; 249: G649. 